Ivano Cardinale $^{1}$ and Roberto Scazzieri ${ }^{2}$

\title{
EXPLAINING STRUCTURAL CHANGE: ACTIONS AND TRANSFORMATIONS ${ }^{3}$
}

\section{Introduction}

At least since classical political economy, studies of the medium- and long-term dynamics of economic systems have highlighted the relationship between changes in the magnitude of economic variables and changes in their composition. Adam Smith associates the changes in the magnitudes of the social product with changes in the relative proportions of productive sectors such as the proportion between agriculture and manufacturing (Smith, 1976 [1776], Book III 'Of the Different Progress of Opulence in Different Nations’). David Ricardo associates an increasing social product with changing proportions between labour and produced means of production under conditions of limited availability of agricultural land (Ricardo, 1951 [1817], Chapter II 'On Rent'). By associating economic dynamics with structural change, that is, with changes in the relative proportions between sectors of the economy, these classical contributions explored, with reference to an expanding economy, a general principle already identified by Pierre de Boisguillebert, according to which 'it is thus proportions that make the whole wealth' (Boisguillebert, 1843 [1707], p. 279) ${ }^{4}$. This point of view is again apparent in the structural theories of economic fluctuations of the late $19^{\text {th }}$ and early 20 ${ }^{\text {th }}$ century (Tugan Baranovsky, 1913 [1894]; Aftalion, 1913; Robertson, 1915; Bouniatian, 1922 [1907]), in the mid- and late-20 $0^{\text {th }}$ century theories of sequential change on transitional paths (Hicks, 1965, 1973, 1985; Dahmén, 1970 [1950]) and in $20^{\text {th }}$ century theories of structural economic dynamics (Pasinetti, 1965, 1981, 1993; Leon, 1967; Lowe, 1976; Quadrio Curzio, 1986; Quadrio Curzio and Pellizzari, 1999).

More specifically, a common feature of the aforementioned theories is that relative proportions must remain within a range of feasible transformations. This highlights an important feature of structural change: not all system components can change at the same time and/or at the same speed. In other words, a principle of relative structural invariance is in play behind the

\footnotetext{
${ }^{1}$ Goldsmiths, University of London.

${ }^{2}$ Department of Economics, University of Bologna and National Lincei Academy; Gonville and Caius College and Clare Hall, Cambridge.

3 The authors are grateful to participants in the 'Structures and Transformations' conference at the Centro Linceo Interdisciplinare 'Beniamino Segre', National Lincei Academy, for stimulating discussion and comments. We also acknowledge with thanks the insightful comments and suggestions of two anonymous referees. The usual caveat applies. 4 '[c]e sont donc les proportions qui font toute la richesse' (Boisguillebert, 1843 [1707], p. 279).
} 
transformations of most economic structures (Landesmann and Scazzieri, 1990, 1996; Scazzieri, 2018a, 2018b). By relying on this principle, theories of structural change can explain the way in which economic dynamics entails changes across system components (for instance, different speeds of change across different industries). Therefore, they can explain the range of changes that is made possible by given economic structures. However, in order to move from identifying a range of possibilities to specifying a path of change out of those which are possible, these theories make explicit or implicit assumptions about actions taking place within structures. This, we argue, suggests that structural change is to some degree open-ended: existing structures specify ranges of possibilities, not the specific actions taken therein. Therefore, they specify potential rather than actual dynamics. It is in historical contexts that the actual path of structural change is determined, once actors have performed specific actions instead of others. But this is determined ex post, not ex ante. Far from being a limitation, this is a defining feature that makes it possible to avoid conceiving of structural change as deterministic. Accordingly, we suggest conceiving of theories of structural change as identifying the range of possible changes that might take place depending on the actions carried out within those structures in specific historical contexts. On this view, in order to explain structural change, we need to consider the possibilities opened up by economic structures as well as the actions that take place within those possibilities.

This paper is organised as follows. Section 2 discusses the classical and post-classical theories of structural change, highlighting relative structural invariance as the common ground of theories addressing medium- and long-term structural change. The analysis identifies relative structural invariance as the principle whereby structures determine the range of possible transformations, and examines what individual and/or collective actions are implied in moving from possible transformations to specific paths of structural change. Section 3 addresses the relationship between structural changes in the medium- and long-term and discusses it in terms of plural causality and successive levels of approximation. Section 4 concludes the paper by examining the interplay between actions and structures and argues that this interplay brings to light the central causal framework explaining structural change in given contexts.

\section{Structural Change and Structural Invariance}

\subsection{Classical political economy}

Smith's Wealth of Nations provides an early instance of dynamic analysis focussing on the relationship between system components and the corresponding proportionality conditions. This approach characterizes both his analysis of the long-term dynamics of economic systems and his investigation of the medium-term adjustment of productive units to external shocks. The study of 
long-term dynamics brings Smith to examine the 'natural progress of opulence' of national economies as they move across different stages of development (Smith, 1976 [1776], Book III 'Of the Different Progress of Opulence in Different Nations'). Here Smith identifies structural conditions suggesting a dynamic trajectory characterized by the development first of agriculture, then of manufacturing, and finally of 'carrying trade' (provision of trade services to others):

As subsistence is, in the nature of things, prior to conveniency and luxury, so the industry which procures the former, must necessarily be prior to that which ministers the latter. The cultivation and improvement of the country, therefore, which affords subsistence, must, necessarily, be prior to the increase of the town, which furnishes only the means of conveniency and luxury. It is the surplus produce of the country only, or what is over and above the maintenance of the cultivators, that constitutes the subsistence of the town, which can therefore increase only with the increase of this surplus produce. (Smith, 1976 [1776], III.1.2, p. 377)

According to the natural course of things, therefore, the greater part of their capital of every growing society is, first, directed to agriculture, afterwards to manufactures, and last of all to foreign commerce. This order of things is so very natural, that in every society that had any territory, it has always, I believe, been in some degree observed. Some of their lands must have been cultivated before any considerable towns could be established, and some sort of coarse industry of the manufacturing kind must have been carried on in those towns, before they could well think of employing themselves in foreign commerce. (Smith, 1976 [1776], III.1.8, p. 380).

The above sequence of production regimes reflects the structural conditions governing the formation of the social product. In a first stage of development, the provision of subsistence goods is of primary importance, and takes precedence over manufacturing and external trade. Once subsistence is achieved, the most effective (that is, growth-enhancing) advances in production are best obtained by developing manufactures, as it is in these activities that division of labour can be carried out to the highest degree. Finally, external trade can allow further growth in national wealth even in production regimes that have fully used the advantages of division of labour in manufacturing. This sequence highlights the proportionality changes the economic system should introduce to achieve maximum growth while ensuring the sustainability of the dynamic process under consideration (the economy is able to replace its produced means of production from one period to the next). Smith's natural progress of opulence highlights the proportionality conditions that should govern structural change on a sustainable (self-replacing) maximum growth trajectory. Smith acknowledges that these conditions may or may not be satisfied: 
[T]hough this natural order of things must have taken place in some degree [in any society that had any territory], it has, in all the modern states of Europe, been, in some respects, entirely inverted. The foreign commerce of some of their cities has introduced all their finer manufactures, or such as were fit for distant sale; and manufactures and foreign commerce together, have given birth to the principal improvements of agriculture. (Smith, 1976 [1776], III.1.8, p. 380)

Smith's argument suggests that an economy may avoid following the 'natural' trajectory only if an alternative way of satisfying the proportionality conditions is found. The 'progress of opulence' achieved by certain medieval city states in Europe (such as Genoa, Venice, and the Hansa League cities) inverted the natural sequence by first developing external trade, and yet this can be retrospectively explained by institutional and political contexts that allowed the provision of staple goods in the absence of agricultural development prior to foreign commerce and manufacturing development. Thus, the proportionality conditions could be satisfied even in economies that were following a dynamic trajectory different from the natural one.

Smith's investigation of medium-term dynamics provides another instance of a proportionality condition at play. Here, however, the internal structure of the manufacturing process takes centre stage and the focus of explanation shifts from the identification of a law-based (nomological) causal mechanism to the reconstruction of a context-specific causal path ${ }^{5}$ :

Such fluctuations [in the market price of any commodity] affect both the value and the rate either of wages or of profit, according as the market happens to be either overstocked or understocked with commodities or with labour; with work done, or with work to be done. A public mourning raises the price of black cloth (with which the market is almost always understocked upon such occasions), and augments the profits of the merchants who possess any considerable quantity of it. It has no effect upon the wages of the weavers. The market is understocked with commodities, not with labour; with work done, not with work to be done. It raises the wages of journeymen tailors. The market is here understocked with labour. There is an effectual demand for more labour, for more work to be done than can be had. It sinks the price of coloured silks and cloths, and thereby reduces the profits of the merchants who have any considerable quantity of them upon hand. It sinks, too, the wages of the workmen employed in preparing such commodities, for which all demand is stopped for six months, perhaps for a twelvemonth. The market is here over-stocked both with commodities and with labour. (Smith, 1976 [1776], I.7.19).

\footnotetext{
${ }^{5}$ See Glennan, 1996, 2010, 2017 for a discussion of causal mechanisms, and Pearl, 2009 for a discussion of causal paths distinct from a purely nomological approach to causality. The reconstruction of context-specific causal paths may require the switch from 'simultaneous' to 'recursive' (one-way) causal relationships, as discussed in Pasinetti (2018 [1965]); see also Bellino, Nerozzi and Zoia, 2018).
} 
The above passage calls attention to the proportionality criterion that needs to be satisfied if a production structure is to adjust to changing demand conditions while also meeting existing structural invariance constraints. The distinction between 'work done' and 'work to be done' highlights the time structure of the production process considered as a sequence of fabrication stages (Bianchi, 1984; see also Landesmann and Scazzieri, 1996). Any given stage of fabrication may alternatively hinder or allow further transformations depending on the way in which the precedence pattern between subsequent fabrication stages is arranged (Scazzieri, 1993). Smith’s analysis of medium-term dynamics highlights structural change as a process in time (see also Hagemann and Scazzieri, 2009). This turns relative structural invariances into a condition that determines different speeds of adjustment across different forms of production organisation.

Ricardo’s approach to economic dynamics is close to Smith's in that it allows a distinction between the identification of a causal mechanism (that is, of proportionality conditions determining the range of feasible transformations) and the reconstruction of a causal path (that is, of the sequence of transformation stages following a given trigger and unfolding under given proportionality conditions). Ricardo's theory of capital accumulation, growth and rent formation under limited availability of agricultural land addresses structural change from the standpoint of the proportionality conditions that constrain the economic system along a dynamic trajectory in which more costly techniques are added to less costly techniques as the social product is increased (Ricardo, 1951 [1817], Chapter II ‘On Rent’; see also Quadrio Curzio, 1967, 1986, 1996; Scazzieri, 1993; Scazzieri, Baranzini and Rotondi, 2015):

On the first settling of a country, in which there is an abundance of rich and fertile land, a very small proportion of which is required to be cultivated for the support of the actual population, or indeed can be cultivated with the capital which the population can command, there will be no rent; for no one would pay for the sue of land, when there was an abundant quantity not yet appropriated, and, therefore, at the disposal of whosoever might choose to cultivate it [...] If all land had the same properties, if it were unlimited in quantity, and uniform in quality, no charge could be made for its use, unless where it possessed peculiar advantages of situation. It is only, then, because land is not unlimited in quantity and uniform in quality, and because in the progress of population, land of an inferior quality, or less advantageously situated, is called into cultivation, that rent is ever paid for the use of it. When in the progress of society, land of the second degree of fertility is taken into cultivation, rent immediately commences on that of the first quality, and the amount of that rent will depend on the difference in the quality of these two portions of land. (Ricardo, 1951 [1817], p. 70) 
This approach highlights the dynamics of economic structure in the light of proportionality conditions and land availability constraints requiring the economy to introduce discrete changes of production technique as the scale of production is continuously increased. Limited land availability under the proportionality conditions associated with a given technology in use may lead to one or another decreasing returns trajectory depending on the way economic actors are assumed to deliver an increasing agricultural output in a given institutional setting. Ricardo's decreasing returns trajectory reflects the working of technological proportionality and land availability conditions under the assumption that economic dynamics is triggered by capitalist entrepreneurs acting in a perfectly competitive setting. Under this assumption, the rate of profits is equalized across the different production techniques in operation independently of their respective cost effectiveness, and rents arise (at different rates) for all techniques more cost-effective than the marginal one. The above set of assumptions generates the classical Ricardian decreasing returns trajectory, along which increasing levels of agricultural output are associated with a decreasing rate of profits (uniform across all techniques in use) and with an increasing total rent income, even if the latter is unevenly distributed across the different techniques depending on their respective degree of cost effectiveness. Actions and institutions different from those assumed by Ricardo's would generate decreasing returns trajectories different from the one described above. For what concerns institutions, for example, if the rate of profit is inversely related to the unit wage, there will be a degree of freedom that would make the economy follow one or another dynamic trajectory depending on the income distribution between wages and profits (Quadrio Curzio, 1967, 1996, pp. 119-122). For what concerns actions, Ricardo's dynamic trajectory assumes that capitalists cultivate additional land following the order of fertility, rather than another criterion. Therefore, proportionality conditions and availability constraints highlight a set of feasible motions within economic structure. These motions mutually constrain one another so that the economy can only move within a limited range of feasible transformations. However, proportionality conditions and availability constraints are not enough to determine the trajectory the economy will follow under given circumstances. The Ricardian decreasing returns trajectory is only one of the different structural dynamics the economy may follow when the set of techniques is given and the availability of primary (non-produced) resources is limited, depending on different assumptions about institutions and actions (Scazzieri, 1993; Quadrio Curzio and Pellizzari, 2018).

The chapter of Ricardo's Principles devoted to the analysis of the 'temporary reverses and contingencies, produced by the removal of capital form one employment to another' (Ricardo, 1951 [1817], Chapter XIX 'On Sudden Changes in the Channels of Trade, p. 263') switches from long- 
term to medium-term dynamics and investigates the causal path triggered by a 'revulsion of trade' under proportionality constraints that generate a definite time sequence of adjustments along the transitional path followed by the economy in its motion from one settled situation to another:

The commencement of war after a long peace, or of peace after a long war, generally produces considerable distress in trade. It changes in a great degree the nature of the employment to which the respective capitals of countries were before devoted, and during the intervals while they are settling in the situations which new circumstances have made the most beneficial, much fixed capital is unemployed, perhaps wholly lost, and labourers are without full employment [...] In rich and powerful countries, where large capitals are invested in machinery, more distress will be experienced from a revulsion in trade, than in poorer countries where there is proportionally a much smaller amount of fixed, and a much larger amount of circulating capital, and where consequently more work is done by the labour of men. It is not so difficult to withdraw a circulating as a fixed capital, from any employment in which it may be engaged. It is often impossible to divert the machinery which may have been erected for one manufacture, to the purposes of another. (Ricardo, 1951 [1817], pp. 265-266)

Ricardo’s approach to the medium-term dynamics triggered by 'the commencement of war after a long peace, or of peace after a long war' is remarkably similar to Smith's analysis of the consequences of a 'public mourning' as in both cases the productive structure of the economy is supposed to follow a definite time path of adjustment. Both Smith and Ricardo highlight that different speeds of adjustment are associated with different structures of the production process. In Smith, the speed of medium-term structural change is higher the greater the proportion of work to be done to work done; in Ricardo, structural change is swifter in the case of a high proportion of circulating to fixed capital. In either case, relative structural invariance determines the time profile of structural change.

In conclusion, classical economic theory highlights the role of proportionality conditions in explaining both long-term and medium-term structural change. Long-term dynamics is addressed highlighting the hierarchy of motions of different subsystems in the economy (say, of different industries). This hierarchy reflects the interdependencies between subsystems and is independent of specific dynamic impulses (such as Smith’s ‘public mourning’, Ricardo’s ‘commencement of war after a long peace, or of peace after a long war', or a change in production technique). Medium-terms dynamics is investigated considering the sequence of stages characterizing the dynamic trajectory of the economy as it moves from one settled position to another. This sequence reflects both the dynamic impulse and the bottlenecks due to the hierarchy of motions, for these bottlenecks constrain the way 
in which the impulse works itself out within the existing structure. In short, proportionality conditions determine the range of motions and transformations that are feasible in the medium- and long-term for an economy affected by a dynamic impulse, such as population increase under limited land availability or increasing extent of the market. At the same time, the structural change trajectory followed by the economy would reflect the interplay between those feasible motions and specific if sometimes implicit assumptions concerning, for example, capitalists' actions on a Ricardian decreasing returns trajectory or a modular social structure allowing the reshuffling of labour patterns and labour specialization on a Smithian increasing returns trajectory ${ }^{6}$.

\subsection{Economic Fluctuations and Medium-Term Dynamics}

The horizontal scheme of circular interdependence between productive sectors (or 'industries') and the vertical scheme of one-way linkages between the construction of capital goods and the utilization of those goods to produce final products are fundamental building blocks of a structural theory of medium-term dynamics ${ }^{7}$. The integration of the two schemes is necessary once we consider the conditions for the synchronization over time of interdependent production processes employing capital goods of different time durations and turnover periods. The analysis of these conditions identifies relative structural invariance as a principal feature of economic fluctuations, which provides an analytical bridge between classical economic theories and the later theories of medium-term dynamics (see also Cardinale and Scazzieri, 2017). The Classical Economists identified the tension between the conditions for the dynamic synchronization of a production economy and the different degrees of durability of productive assets (such as the different degrees of durability of circulating vs. fixed capital goods). Karl Marx worked in this analytical tradition and highlighted the time asymmetries between elements of production as the technical condition leading to the mediumterm dynamics of an industrial economy. Different turnover periods between circulating (fluid) capital and fixed capital are of central importance: '[t]he fluid capital entering the production process transfers its whole value to the product, and must therefore be constantly replaced in kind by the sale of that product, if the production process is to continue without interruption. The fixed capital entering the production process transfers only part of its value (the wear and tear) to the product, and continues

\footnotetext{
${ }^{6}$ In a modular social structure any actor 'had to choose his productive activity and his methods independently, in the light of his own aims and assessments of the circumstances, rather than have them dictated by his status, his location in the social hierarchy, his guild membership and so forth’ (Gellner, 1998, p. 26).

7 The circular scheme goes back to Quesnay’s Tableau économique (Quesnay, 1758) and Marx's reproduction schemes (Marx, 1978 [1887]). Its current analytical formulation is due to the work of scholars such as Wassily Leontief (1928, 1941) Jan von Neumann (1935-37), Piero Sraffa (1960). The vertical scheme goes back to the classical Austrian analysis of the time-structure of production (Böhm-Bawerk, 1889; Hayek, 1931, 2008 [1941]). Methods to integrate circular and vertical approaches to production interdependencies are outlined in Nurkse (1935), Pasinetti (1980 [1973], 1988), Quadrio Curzio (1975, 1986), Lowe (1976), Hicks (1985), Landesmann and Scazzieri (1996), Baldone (1996), Quadrio Curzio and Pellizzari (1999, 2018), and Cardinale and Scazzieri (2016).
} 
to function in the production process despite this wear and tear; hence it only needs to be replaced in kind at shorter or longer intervals, in any case not as often as the fluid capital' (Marx, 1978 [1887], p. 262). Fixed capital items do not need frequent replacement as circulating capital items, which entails the mismatch between the dates of physical replacement for fixed capital. This leads Marx to highlight reinvestment cycles of fixed capital as the 'material foundations for the periodic cycle in which business passes through successive periods of stagnation, moderate activity, overexcitement and crisis' (Marx, 1978 [1887], p. 264). This technical constraint works in the socio-institutional setting of a capitalist economy, which is characterized by the 'constant revolutionizing of the means of production, which [...] increases steadily with the development of the capitalist mode of production’ (Marx, 1978 [1887], p. 264). The medium-term dynamics of a capitalist economy is triggered by the interplay of material (technical) and economic conditions. Reinvestment cycles are different for different fixed capital goods. On the other hand, technical progress (the 'constant revolutionizing of the means of production') reduces the turnover periods of fixed capital items. The combination of different reinvestment cycles durations and technical progress determines the overall instability of industrial capitalism. In this institutional setting, economic crises (as distinct from pure reinvestment cycles) are the consequence of the greater immobilizations of liquidity between replacement times of fixed capital items and of the large amounts of liquidity made available in a discontinuous way during technological revolutions.

The role of fixed capital items and the discontinuous character of their liquidation phases is at the core of Mykhaylo Ivanovich Tugan Baranovsky’s study of industrial crises in England (Tugan Baranovski, 1894; 1913 [1900]). In this work, Tugan Baranovsky highlights that modern industrial technology leads to a specific allocation of liquidity between circulating and fixed capital. This allocation of liquidity leads to the uneven distribution of investment across production processes characterized by different time profiles and makes possible the mismatch between the capital available and the capital in use at any specific phase of the trade cycle. This framework provides the analytical starting point of Tugan Baranovsky's reconstruction of industrial crises in England. Economic structure is characterized by 'the reciprocal dependence, in the capitalist economic order, of the industrial branches upon one another' (Tugan Baranovsky, 1913 [1900], p. 257). This 'reciprocal dependence' makes every production to generate 'a demand for other commodities [...] In order to produce new commodities, it is necessary to have raw materials, means of production, consumer goods for workers. The expansion of production in any branch thus generates the demand for commodities produced by other industries. In this way, the impulse that determines the production increase spreads from one industrial branch to another' (Tugan Baranovsky, 1913 [1900], pp. 257258). Interdependence makes possible different dynamic patterns and propagation mechanisms 
depending on the stage of technological and economic development. Production technologies involving a high proportion of fixed to circulating capital explain 'why, in periods of expanding fixed capital investment, one witnesses a generalized increase of demand for all commodities' (Tugan Baranovsky, 1913 [1900], pp. 257-58). Fixed capital investment leads to time asymmetries between the response mechanisms of different sectors to given impulses (such as an increase or fall of consumer demand). At the same time, liquidity formation in a capitalist economy results from actions that are to a large extent independent of the specific investment requirements of sectors: 'The greatest part of the loanable capitals available on the market does not derive from individual incomes; it is formed by capitalized incomes that, for one reason or another, have not been invested at their source. Now, one should not confuse the accumulation of this loanable capital with the growth of productive capital' (Tugan Baranovsky, 1913 [1900], pp. 258-59). Therefore, medium-term dynamics is characterized by the non-proportional expansion of productive capital across industrial sectors. This is due to the joint working of technical conditions (liquidity immobilizations in fixed capital goods) and economic actions independent of the reinvestment requirements of the fixed capital goods sector. The resulting medium-term dynamics is characterized by fluctuations in the level of economic activity different from the reinvestment cycles of fixed capital goods (machinery). Yet, investment in machinery makes the price of iron a particularly informative indicator of the state of the economy during fluctuations in activity levels:

' $[t]$ he most characteristic feature of industrial fluctuations is the coincidence of the extremely regular movement of the price of iron with the phases of the industrial cycle: in the phase of economic expansion the price of iron is invariably high, whereas in the phase of industrial stagnation it is extremely low’ (Tugan Baranovsky, 1913 [1900], p. 252).

The responsiveness of iron prices to changes in the level of economic activity reflects implicit assumptions concerning the interplay of the structural conditions determining the order of motion of different types of production with the actions of entrepreneurs reacting to an increase in the profitability of investment in the fixed capital goods sector relative to that in the consumer goods sector. In an economy moving towards the downturn, the higher relative profitability of investment in fixed capital goods makes investment in these goods attractive to loanable funds (Tugan Baranovsky, 1913 [1900], pp. 253-254). However, saving decisions are independent of investment decisions, so that it is necessary to assume a specific match between savers' and investors' behavior to generate the medium-term dynamics characterizing Tugan Baranovsky’s trade cycle. This means that entrepreneurs' propensity to invest needs to match the availability of loanable funds. In addition, institutional conditions must allow entrepreneurs to invest according to the relative profitability of investment in the different sectors of the economy. In short, '[d]uring the phases of prosperity, the 
new fixed capital of society is being created. Social industry as a whole takes a new direction: the fabrication of means of production moves to the foreground. The production of iron, machines, tools, ship, building materials, becomes much more important than in the past. Eventually, the construction of the new fixed capitals is completed: we have new factories, new houses, new ships, and new railways. However, at this point new enterprises become less frequent. There a fall of demand for all materials entering the formation of fixed capital. The distribution of production is no longer proportional [across productive sectors]: machine tools, iron, tiles, and wood for construction are in less demand than in the past since new enterprises are less frequent. However, the producers of means of production cannot withdraw their capital from their enterprises, and the importance of capital invested in constructions, machinery and so forth is such that production is made to continue [...] We have thus overproduction of means of production. The different industrial branches are dependent upon each other, and partial overproduction leads to general overproduction' (Tugan Baranovsky, 1913 [1900], p. 271).

Mentor Bouniatian takes a similar view of the relationship between technical constraints and socioeconomic dynamics. He emphasizes that, when economic expansion ends, there is shortage of liquidity as shortage of free purchasing power due to 'overcapitalization' (Bouniatian, 1922 [1907], pp. 262-269). At this time, 'the national economy has at its disposal means of production greatly in excess of the possibility of full and profitable utilization under the consumption conditions resulting from the existing economic structure, mode of production and realization, distribution of wealth and accumulation of capital’ (Bouniatian, 1922 [1907], p. 269). In this case, liquidity shortage reflects a social condition rather than a technical bottleneck. For overcapitalization 'does not mean that capital quantitatively exceeds the level above which it cannot find employment in an absolute sense [...] [W]hat is essential is that the absolute value of capital does not correspond any longer, under the given conditions of consumption, to the standards existing when that capital was formed. We are dealing here with a phenomenon of a social character' (Bouniatian, 1922 [1907], pp. 269-70). The interplay of technical and social conditions is also apparent in the way the economic downturn brings about a correction of overcapitalization. Here two distinct mechanisms are at work. On the one hand, 'superfluous capital' starts being scrapped as soon as 'overproduction and selling difficulties begin to appear' (Bouniatian, 1922 [1907], p. 270). On the other hand, falling prices during the crisis bring about a change in the 'distribution and utilization of purchasing power' (Bouniatian,1922 [1907], p. 275). This is because falling prices 'bring about a fall in the purchasing power of producers and capitalists to the advantage of the class of consumers at large. This diffusion of purchasing power encourages consumption exactly as its concentration in an expansion period would have stimulated capital accumulation' (Bouniatian, 1922 [1907], p. 275). To sum up, Bouniatian considers the tension 
between individual motives and social constraints as the most important trigger of periodical crises: the 'unlimited tendency to accumulate within individual economic units would clash with the existence of a check upon social capitalization when 'social consumption' does not grow at the same rate as private capital accumulation' (Bouniatian, 1922 [1907], p. 361). At the root of this tension between individual actions and social outcomes is the dual character of the accumulation of capital in a private ownership economy. Private capital accumulation is necessary condition to the survival of individual capitalists ${ }^{8}$. But accumulation can take two different avenues: 'First, through the creation of productive goods; second, through the acquisition of priority rights in the distribution of the social product resulting from possession of real elements of production [...] or in the acquisition of rights on the property and incomes of other individuals' (Bouniatian, 1922 [1907], p. 317). The consequences of this dichotomy are far reaching: 'In the former case, there is formation of social capital, that is, society as a whole becomes better endowed through productive installations and commodity reserves that increase the social product. In the latter case, there is accumulation of a purely private capital, that is, acquisition of rights on existing sources of income to the advantage of particular individuals’ (Bouniatian, 1922 [1907], p. 317). In other words, there is no necessary link between the accumulation of private capital and the accumulation of social capital, even if the average rate of private capital accumulation is bounded above by the rate of increase of social capital: 'If [an individual economic unit] increases its capital in a non-proportional way relative to its own consumption, this is only possible if other units correspondingly increase their consumption, or, in the case of constant [aggregate] consumption, if the capital of other economic units is excluded from production to a corresponding degree' (Bouniatian, 1922 [1907], p. 320). This relationship is the root mechanism generating economic crises: '[w]hen this tendency towards the accumulation of capital without a corresponding increase of consumption develops in all economic units, or in many those units, [this tendency] would necessarily lead to general overcapitalization’ (Bouniatian, 1922 [1907], p. 320 $)^{9}$. The lack of correspondence between private and social capital accumulation is also central to explaining the recurrence of crises in the world economy: 'the different national economies find themselves, from the point of view of the struggle for capitalization, in the same situation of private economic enterprises if each one of them were individually considered’ (Bouniatian, 1922 [1907], p. 371; see also Bouniatian, 1928; Besomi, 2007). The lack of correspondence between private and

\footnotetext{
${ }^{8}$ As noted by Albert Schäffle '[t]he capitalist is bound to die in his violent struggle for existence with stronger rivals unless he is constantly increasing his capital' (Schäffle, 1896, tome II, p. 281; see also Bouniatian, 1922 [1907]).

${ }^{9}$ Bouniatian's argument is closely related to John Maynard Keynes's later criticism of the fallacy of composition: 'I have called my theory a general theory. I mean by this that I am chiefly concerned with the behavior of the economic system as a whole, - with aggregate incomes, aggregate profits, aggregate output, aggregate employment, aggregate investment, aggregate saving [...] And I argue that important mistakes have been made through extending to the system as a whole conclusions which have been correctly arrived at in respect of a part of it taken in isolation’ (Keynes, 1973 [1939], p. xxxii).
} 
social accumulation in each economy individually considered finds a counterpart in that between private and social accumulation across different economies. This dichotomy is responsible for recurrent overcapitalization crises at the level of the world economy. As a result, it is possible to overcome economic crises only when the distribution of saving and investment actions across the different actors in the economy (or across the different national economies) allows social consumption to be adjusted to the overall rate of capital accumulation.

The interplay of structural constraints and assumptions on actions and institutions also characterizes subsequent contributions to the theory of medium-term dynamics, such as those of Friedrich August von Hayek and John Hicks. Hayek’s explanation if medium-term fluctuations is based on the consideration of structural adjustment to the production process resulting from 'any sort of change' (Hayek, 2008 [1941], p. 275). A clear appraisal of the dual explanation needed for the analysis of medium-term structural dynamics is outlined in Chapter 23 of Hayek's Pure Theory of Capital, which is devoted to 'The Effects of Unforeseen Changes and in Particular of Inventions'. There Hayek considers 'the case where the absolute amount of operating costs, as well as their relative share in the total cost of a unit of the product, is greater in the case of the new process than in the case of the old process' (Hayek, 2008 [1941], p. 292). Under these essentially technical conditions, 'what actually happens is that, as the old equipment wears out and is replaced by equipment requiring the investment of a smaller amount of input, but co-operating with a greater amount of current input, the aggregate of the investment periods of this input is shortened... [S]ince in the aggregate (or on average) this input would mature sooner than it did in the past, the flow of the final services obtained from it would not dovetail but would partly overlap with those of the old equipment' (Hayek, 2008 [1941], p. 293). Under these conditions, 'it will be necessary to reinvest in the new equipment at a slower rate but over a longer period' to avoid a situation in which 'the supply of [output by the new process] would temporarily be increased beyond the level at which it could be permanently maintained' (Hayek, 2008 [1941], p. 293). Therefore, Hayek’s approach highlights conditions about actions that are necessary in order to maintain the economic system's ability to reproduce itself at a given level of activity.

Hicks's theory of the medium term is focused on analysis of the transitional path (traverse) from one fully settled position to another after a source of change shifts the economy away from its previous trajectory (Hicks, 1973, 1977, 1985). A characterizing feature of Hicks's traverse analysis is the consideration of the technical bottlenecks due to the time-profile of capital-using processes, which leads him to distinguish between a 'construction phase' and a 'utilization phase' of the production process. This time structure introduces a precedence pattern between stages of the production process and determines a sequence of feasible trajectories, which the economy may or 
may not follow depending on actions and institutions. Hicks's way of selecting specific transitional paths out of a variety of feasible trajectories is by introducing assumptions that make a single trajectory possible. This approach leads him to investigate two alternative transitional paths, respectively called 'Full Performance' (or 'Fixwage') Path and 'Full Employment' Path (Hicks, 1973). The former is a traverse on which 'the wage is given exogenously- being determined in some way outside the model' and a 'perfectly elastic supply of labour, at the given wage, must [...] be included' (Hicks, 1973, p. 48) while on the latter 'the rate of expansion of the labour supply is given, and the whole of the given labour force is to be kept fully employed' (Hicks, 1973, p. 48). The 'Full Performance' Path is a structural change trajectory close to Smith's and Ricardo's assumptions on medium-term dynamics; it assumes that capitalists' saving behaviour allows the full utilization of the economic system's productive capacity. The 'Full Employment' Path, in contrast, could be the structural change trajectory of an economy in which policy-makers pursue Keynesian full employment policies. In either case, medium-term dynamics is determined by actions and institutions that keep the economy on a given transitional path to the exclusion of other paths that may be feasible under the existing technical conditions.

\subsection{Structural Economic Dynamics}

Classical political economy explains structural change in terms of proportionality conditions determining the way existing structures adjust to temporary or persistent sources of change. As we have seen, the classical approach to medium-term dynamics sees structural change as a sequence of transformation stages leading the economy from one settled position to another along a trajectory driven by some initial disturbance. In contrast, the classical approach to long-term dynamics views structural change as a trajectory in which economic structure is modified because of a persistent change of fundamental parameters (be it the pattern of division of labour between productive processes, or the scarcities of different resources). In short, medium-term dynamics investigates the adjustment process between different settled positions of the economy, whereas long-term dynamics considers the dynamic trajectory generated by the succession of settled positions associated with a corresponding succession of fundamental parameters. In medium-term dynamics, structural change is explained by identifying the hierarchy of motions that constrains economic dynamics within a feasible range following a given disturbance. This hierarchy reflects a condition of relative structural invariance but is not by itself enough to determine the dynamic course of the economy, which requires specific assumptions on actors' behaviour following the initial disturbance. In contrast, when it comes

to explaining long-term structural change, classical theories take a different route. In this case, 
structural change is explained by constructing an analytical template showing how economic structure would change if we were to assume the persistent operation of some dynamic principle such as Smith's division of labour, or Ricardo’s increasing use of lands of inferior quality. The classical theory of long-term structural change highlights trajectories that may be different from the dynamic paths followed by real economies. Thus, Smith's 'natural progress of opulence' may be inverted if external trade and manufacturing are developed before the primary sector, and Ricardo’s decreasing returns trajectory may be avoided if enough land of the most fertile type is available. However, the analytical template constructed in terms of specific assumptions may be used to identify the conditions under which alternative trajectories are feasible.

Modern theories of long-term structural change follow the classical approach by considering hypothetical trajectories instead of actual processes of adjustment to changing conditions. However, a characterizing feature of those theories is the explicit distinction between different layers of economic structure. Luigi Pasinetti's 'separation theorem' is a case in point (Pasinetti, 2007). Pasinetti distinguishes between a 'fundamental' level of investigation that addresses the persistent and general features of an industrial economy, and a level of investigation addressing features of economic structures that are more contingent and likely to reflect specific historical and institutional contexts. This approach builds on classical political economy but introduces a profound change with respect to its original focus. For in this case the theory of long-term structural dynamics is explicitly removed from the analysis of the actual historical changes it nevertheless aims to explain (Pasinetti, 1981, Chapter 10). Pasinetti's separation between the 'natural' and the 'institutional' features of the economy brings to light a distinction that was already implicit in the classical approach. It also makes it possible to explain structural change in a new light, as it distinguishes between the proportionality conditions embedded in existing structures and the human actions that are required to drive the economy along a specific trajectory. One important consequence of that distinction is recognition that the proportionality conditions, which are themselves an expression of relative structural invariance, are compatible with a variety of dynamic trajectories. Pasinetti examines in detail the structural change trajectory (which he calls 'natural') that allows full employment of the labour force and full utilization of productive capacity under conditions of technical progress and Engel-law type changes of consumer preferences. However, he also acknowledges that the 'natural' dynamics may not be the one followed by the economy (Pasinetti, 1981, Chapter 10). In conclusion, the distinction between 'natural' dynamics and actual dynamics highlights the open-endedness of structural constraints and the plurality of trajectories the economy may follow subject to any given set of productive interdependencies. A Pasinetti-type economy may or may not follow the structural changes required on the 'natural' path depending on whether the actions that take place in that economy are or are not 
consistent with Pasinetti's fundamental macroeconomic condition for full employment and full capacity utilization. If they are not, the economy may follow a plurality of structural change trajectories that are consistent with the evolution of structural parameters (production coefficients and per capita consumption coefficients) without achieving full employment and full capacity utilization $^{10}$.

The distinction between the hypothetical trajectory allowing a 'desired' state to be attained and the multiplicity of alternative trajectories open to the economy subject to given proportionality conditions is further explored by Alberto Quadrio Curzio Quadrio Curzio highlights that limited availability of non-produced means of production (such as land or energy sources) constrains the economy to follow a structural change trajectory using increasingly less effective (i.e., costlier) techniques as the overall scale of production is increased. A remarkable feature of this investigation is that, contrary to the original decreasing returns trajectory considered by Ricardo, here a variety of trajectories is shown to be feasible, under any given set of technological parameters, depending on the type of distribution between different income categories (wages, profits and rents). Changes in income distribution may be associated with changes in the efficiency ranking of techniques, which may in turn lead to changes in the activation sequence of the different techniques along a trajectory aimed at achieving maximum feasible growth. This analysis highlights the uneven pattern of structural change under scarcity constraints due to the interdependencies between production processes. It also shows that intermediate goods that are redundant under certain technological conditions (thereby generating residuals) may again become usable in a different technological setting (Quadrio Curzio, 1986; Quadrio Curzio and Pellizzari, 1999). In this case, the same structural change trajectory may show alternating phases of decreasing and increasing returns depending on whether the dominating influence is the switch to less effective (i.e., costlier) technique or the possibility of using residuals to increase the economy's growth rate. The cleavage between what is feasible under any given set of productive interdependencies and what can happen depending on institutional conditions and actors' objectives is a characteristic feature of this investigation (Quadrio Curzio and Pellizzari, 2018). The structural dynamics trajectory followed by any given economy is shown to reflect both the technological interdependencies between production processes and the institutional and historical conditions influencing the objectives of "macro decision-makers" and the actual sequence by which production structures are changed.

\footnotetext{
10 Therefore, specific assumptions on actions and institutions are required to 'close' structural dynamics along a determinate path. This is shown, for example, in Paolo Leon's theory of structural dynamics under capitalist conditions, in which the economy can follow a trajectory of proportional changes consistent with Engel's law subject to the condition of foresightedness of capitalists as a social group (Leon, 1967).
} 
The foregoing analysis suggests that interdependencies bring about a range of feasible transformations, which human actions may or may not take up depending on actors' objectives. This distinction highlights that explaining structural change must follow a dual route depending on whether we consider the structural constraints determining which dynamic trajectories are feasible or the dynamic triggers driving the economy along a specific sequence of transformation stages. Both approaches are needed, because explaining structural change requires both the identification of the causal mechanism associated with the existing set of interdependencies and the reconstruction of the specific causal path followed by the economy. The above two components of structural change are associated with two different ways of representing economic structure. The interdependence between production processes of the same time length (or assumed to be so) highlight a 'horizontal' causal mechanism in which processes are mutually related in terms of a proportionality condition that allows achievement of a systemic objective such as the ‘viability' of the set of interdependent processes. On the other hand, the relationship between processes (of the same duration or of different durations) that are hierarchically related along a sequence of production stages highlights a 'vertical' causal mechanism, in which processes are mutually related in terms of a proportionality condition governing the rate at which throughput (the flow of goods-in-process) moves from one stage of production to the next. The two causal mechanisms presuppose different proportionality conditions but are jointly at work behind any causal process in which structural transformation takes place.

Adolph Lowe's analysis of structural change combines horizontal and vertical representations of interdependence and highlights the intertwining of horizontal and vertical mismatches along a structural transformation path (Lowe, 1976). Lowe’s representation of productive interdependences in an industrial economy (his 'schema of industrial production') leads him to consider the economy as 'vertically divided into two sectors: equipment-good industries [...] and consumer-good industries [...] described as Sector I and Sector II, respectively' (Lowe, 1976, p. 31). This analytical representation highlights the coexistence of vertical and horizontal product flows coordinated with one another. The transformation flow from natural resources to finished consumer goods presupposes for its continuity a horizontal flow from equipment-goods industries (Sector I) to consumer-goods industries (Sector II) that must be large enough to replace the equipment used up during vertical transformation in the consumer-goods industries (Sector II). Similarly, Sector I must allow a vertical transformation flow that is large enough to replace the equipment goods used up in this sector. However, 'there is an important difference between the two sectors regarding the horizontal flow. In sector II it is a horizontal flow from Sector I that replaces the worn-out equipment. In Sector I the currently used-up equipment is replaced from the output of that sector itself, more precisely, from the output of Subsector Ia. In other words, the horizontal flow consists of a portion of the vertical flow 
“turned back”, that is, it is a circular flow' (Lowe, 1976, p. 33) ${ }^{11}$. This approach allows Lowe to distinguish between 'structure analysis' and 'force analysis', where 'structure analysis' investigates 'the configurations in which the elements of an economic system [...] must be arranged if the transformation of the initial into the stipulated terminal state is to be achieved' (Lowe, 1976, p. 17), while 'force analysis' studies 'the patterns of behaviour or motivation that initiate and sustain the motion of the system along the structurally determined path' (Lowe, 1976, p. 17) ${ }^{12}$.

Lowe's distinction suggests a conclusion that can be extended to structural change analysis as a whole: any structural change process presupposes both the 'horizontal' proportionality condition characterizing a set of mutually related processes, and the 'vertical' proportionality condition characterizing a sequence of temporally related production stages. However, combined horizontal and vertical constraints are not enough to determine the structural change trajectory. Actions are necessary to move from open-ended dynamics to specific paths of structural change.

\section{Bridging Medium- and Long-Term Dynamics: Towards Causal Pluralism}

The foregoing analysis suggests that theories of structural change highlight two different, but closely intertwined, approaches to explaining the transformation of economic structure. One approach looks at structure in terms of a system of interdependencies (a causal mechanism) in which the change of certain magnitudes (such as the unit wage or the rate of technical progress) is associated with changes in other magnitudes (such as the system of relative prices) by virtue of a proportionality condition that binds together the different parts of the economy under a given systemic objective (such as the need to reintegrate productive capacity or to achieve full employment). In this case, structural change is explained by the proportionality condition needed to achieve the systemic objective (say, to achieve full employment) once the change of certain external circumstances is assumed (be it a different population growth rate, a new production technique, or a new energy source). This explanation is relative to the systemic condition the economy is assumed to achieve (such as the ability to reintegrate productive capacity, or full employment) but does not address the process by which structural change may take place. The other approach looks at structural change as a sequence of transformation stages (a causal path). This sequence is triggered by a given dynamic impulse (say, a new production technique, or a new energy source) that drives the economy from one state to another through a sequence of bottlenecks that reflects the hierarchy of feasible motions in

\footnotetext{
${ }^{11}$ Sector I (the equipment-good sector) is itself divided into two subsectors: subsector Ia, which produces equipment used in sector I (equipment-good sector) and sector II (consumer-good sector), and subsector Ib, which produces equipment used in sector II only.

12 This approach is related to Lowe's concept of 'instrumental analysis', which is a type of investigation that 'starts out not from an observed but from a postulated terminal state' (Lowe, 1977, p. 146; author's emphasis) and 'extracts' from knowledge of the internal structure of the economic system the means to achieve that state.
} 
the economy. In this case, structural change is explained by the interplay of two different causal mechanisms: (i) the proportionality condition determining the precedence relations between the different types of motion in the economy (Myrdal, 1939) (say, which components of productive capacity need to increase to allow the increase of other components to take place), and (ii) the actions and institutions that may drive the economy across a given sequence of transformations out of those which are possible given the aforementioned precedence relations. This explanation is grounded in the consideration of motive forces and bottlenecks, which in turn reflect the hierarchical arrangement of processes within the system in which transformation takes place.

Therefore, plural causality is at work in processes of structural change, and this requires a multi-level approach to explanation. The economy's architecture is built on different sets of proportionality conditions, and each set may be associated with a different structural specification of the economy (such as the horizontal and the vertical specifications discussed above). Any given source of change (say, a change of fashion or a technical innovation) may initiate a process of transformations in which both horizontal and vertical constraints are at play, and in which the economy follows a succession of transformation stages compatible with the 'order of sequence' (Myrdal, 1939, p. 27) characterizing its set of feasible motions. Multiple constraints and triggers may be in operation at any given time, so that explaining structural change may require the identification of distinct causal paths, and the investigation of the interaction and feedback mechanisms linking one causal path to another.

Albert Aftalion's theory of economic fluctuations is an instance of the plural causality at work under structural change (Aftalion,1913). Aftalion starts with a vertical specification of economic structure, in which the economy is decomposed into several vertically integrated sectors, each one associated with production of a final consumer good, and each one including the fabrication of its own capital equipment. A source of change arising from final consumer demand (say, a change in fashion) is likely to trigger a succession of transformation stages at which the economy would respond differently depending on which sectors and/or stages of production are primarily affected. The simultaneous existence of vertical constraints linking each production stage to the next and of horizontal constraints linking intermediate goods to a variety of different production lines are at the root of the uneven responses of sectors and/or production stages to sources of change. For example, in a predominantly vertical production structure (a structure in which technical constraints primarily affect the relationship between successive stages of production) 'the price oscillations have each time a less acute character as one moves from one anterior to one posterior industry, from one product to the product that follows it, say from iron ore to cast iron, or from cast iron to iron objects' (Aftalion, 1913, vol. I, p. 109). However, the pattern of responses to a source of change may be different if we 
consider a production structure relying on the supply of intermediate goods to a variety of production lines. In this case, 'the prices of certain products show [...] more pronounced oscillations than products preceding or following them' (Aftalion, 1913, vol. I, ibidem). This is what happens for cast iron 'relatively on the one hand to iron ore and on the other hand to spinning machines or finished products in metal' (Aftalion, 1913, vol. I, ibidem). This also happens 'for cotton and linen tissues relatively on the one hand to unwoven cotton or linen, and on the other hand to cotton fabrics and linen canvas’ (Aftalion, 1913, vol. I, ibidem). Horizontal linkages due to intermediate products provide a privileged transmission channel of changes in activity levels originating somewhere else in the economy.

Fixed capital investment is at the centre of Aftalion's theory of economic fluctuations (Aftalion, 1913, 1927): economic crises are ultimately explained by the longer production time of machinery relative to the other items of the capital stock (see also Scazzieri, 2014). However, the role of fixed capital investment in triggering specific trajectories of uneven medium-term dynamics reflects the interplay of vertical and horizontal constraints in determining the range of feasible motions in the economy. Linkages between successive stages of the same process and between processes activated at the same time bring about a complex hierarchy constraining motions relative to one another. The trajectory followed by the economy reflects actors' behaviour under the above set of dynamic constraints: 'the price fall characterising the crisis and the depression is due to the overproduction of commodities. The price increase characterising prosperity results from underproduction. Human needs are more amply satisfied in one phase of the cycle. They are only insufficiently satisfied in the other' (Aftalion, 1913, vol. II, p. 261). Actions carried out to achieve need satisfaction are central to the type of uneven dynamics that Aftalion describes: 'what matters is not simply lack of equilibrium between industries, but lack of equilibrium between production and needs' (Aftalion, 1913, vol. II, p. 263, emphasis original). To this Aftalion adds that 'We know it is subjective estimates, different from one individual to another, which determine the unique market price, which is an objective phenomenon. The one thousand individual demands add up to determine social demand' (Aftalion, 1913, vol. II, p. 274, added emphasis). In turn, price fluctuations trigger fluctuations in wages, profits and interest, which may influence the dynamics of aggregate demand: ' $[t]$ he rhythm of incomes brings about a rhythm of demand that generalises, intensifies and perhaps lengthens the upward and downward movement of prices' (Aftalion, 1913, vol. II, p. 400). This arrangement of dynamic channels highlights a multi-level causal structure characterised by feedback effects ('reaction de l'effet sur la cause', Aftalion, 1913, vol. II, p.400), which magnify the intensity of medium-term expansion and contraction. Fluctuations in wages, profits and interest also influence long-term phenomena such as demographic trends and technical innovation (Aftalion, 1913, vol. II, 
p. 399), which may in turn affect medium-term dynamics in subsequent periods. In conclusion, bottom-up and top-down processes combine to determine the dynamic trajectory followed by the economy. This provides a bridge between sectoral and macroeconomic dynamics. It also highlights a possible link between medium- and long-term dynamics due to the relationship between machineryintensive technical change and changes in income distribution between categories of consumers. Once again, a plurality of causal factors is in play. On Aftalion's assumptions, on the one hand technical change is likely to accelerate the substitution of capital equipment for labour, thereby increasing (other things equal) the likelihood of economic fluctuations. On the other hand, a contraction of the wage share of national income is likely to diminish (other things equal) the share of machineryintensive consumer goods in aggregate expenditure. This, in turn, may reduce the likelihood of income fluctuations at the level of the macroeconomy.

As Jean Lhomme noted in his essay on Aftalion's method, Aftalion's investigations are pursued through 'successive approximations' (Lhomme, 1945, p. 29). Each level of approximation is essential to understanding the structural dynamics under consideration, and the successive levels of approximation bring structural change analysis closer to historical reality (what is being explained is what happened). And yet, any explanation of structural change is bound to remain open-ended ex ante, because it is the manifold actions on which it is based that will activate a given path of change out of the many that are made possible by economic structures. This is the argument to which the next section is devoted.

\section{Actions, Structures, and the Open-endedness of Structural Change}

In the foregoing sections of the article, we illustrated the open-endedness of structural change in the context of specific theories. We can now provide a more general theoretical argument. Whilst this could be done from different angles (see Cardinale, 2018c), for the purposes of the current paper, it is sufficient to refer to the fact that there is typically no one-to-one correspondence between a system of interdependencies and its analytical representation. For example, a system of interdependent intermediate product flows needed in each other's production may be visualized either as a 'horizontal' system producing $m$ intermediate goods by means of the same intermediate goods, or as a set of $m$ vertically integrated sectors, in which is sector produces the intermediate goods it needs, and is thus independent of the other $m-1$ sectors (Pasinetti, 1980 [1973], 1981; Scazzieri, 1990). In the former case, the economy may be represented by a matrix describing the intermediate product flows in the economy. Matrix A below describes the structure of intermediate product flows in a two goods economy (each element $a_{i j}$ denotes the quantity of good $i$ needed to produce each unity of good $j$ ): 


$$
\mathbf{A}=\begin{array}{ll}
a_{11} & a_{12} \\
a_{21} & a_{22}
\end{array}
$$

In the latter case, the economy may be represented by a set of $m$ vertically integrated sectors describing $m$ lines of productive transformation that coincide with the $m$ goods produced in the economy:

$$
\begin{aligned}
& \boldsymbol{I}(\mathbf{I}-\mathbf{A})^{-1}=\mathbf{v}=\left[v_{i}\right] \quad i=1, \ldots, k \\
& \mathbf{A}(\mathbf{I}-\mathbf{A})^{-1}=\mathbf{H}=\left[\mathbf{h}_{i}\right] \quad i=1, \ldots, k
\end{aligned}
$$

Each vertically integrated sector $i$ is represented by a pair $\left(v_{i}, \mathbf{h}_{i}\right)$. Each $\mathbf{v}_{i}$ 'expresses in as consolidated way the quantity of labour directly and indirectly required in the whole economic system to obtain one physical unit of commodity $i$ as a final good' (Pasinetti, 1980 [1973], p. 20). Each vector $\mathbf{h}_{i}$ 'expresses in a consolidated way the series of heterogeneous physical quantities of commodities 1 , $2, \ldots, m$, which are directly and indirectly required as stock, in the whole economic system, in order to obtain one physical unit of commodity $i$ as a final $\operatorname{good}(i=1,2, \ldots, m)$. This is [a] particular composite commodity, which we shall call a unity of vertically integrated productive capacity for commodity $i(i=1,2, \ldots, m)$ ’' (Pasinetti, 1980 [1973], pp. 20-21).

Whilst it is possible to move back and forth between the horizontal and the vertical representations (Pasinetti, 1981), the two representations call attention to different features of the economy and highlight different opportunities and constraints for human action (Baranzini and Scazzieri, 1990, Cardinale, 2018b). The horizontal representation highlights division of labour between mutually dependent activities (activities needed for each other's functioning), whereas the vertical representation highlights division of labour between sequentially related activities (activities needed along the same sequence of successive production stages).

The two representations, while equivalent from the analytical point of view, highlight different constraints and opportunities. The horizontal representation calls attention to the constraints having to do with the need to coordinate activities simultaneously carried out in the same economy. A central example is the need to keep the system within proportions compatible with its viability, e.g. as specified by the Hawkins-Simon conditions (Hawkins and Simon, 1949). Opportunities have to do with the possibility for a given socio-economic group (e.g. an industry or a class defined on the basis 
of the type of income) to receive a higher share of value added (Cardinale, 2018b). The vertical representation, in contrast, highlights the constraints due to the need to coordinate successive stages of the production process and the need for sufficient effective demand in the macroeconomy. It also reveals opportunities due to growth triggers specific to particular vertically integrated sectors, such as the interdependent and co-evolving processes activated by particular innovations, which Dahmén (1970 [1950], 1984, 1988) identifies as 'development blocks', or to the general state of the macroeconomy, as in the case of macroeconomic stimulus operated through demand of final goods.

Moreover, each representation identifies different socio-economic aggregations as potential carriers of economic interests that face constraints and opportunities (Cardinale, $2018 \mathrm{a}, \mathrm{b}$ ). In the horizontal approach, relevant aggregations can be industries or classes identified on the basis of type of income, depending on whether one assumes uniformity of wage and profit (Cardinale, 2018b, p. 173-4). In the vertical approach, relevant aggregations can be vertically integrated sectors, classes, or the economy as a whole. The fact that aggregations that carry economic interests also depend on the representation of the economy adopted by actors reinforces the argument that we cannot take economic structures as univocally determining action. For example, depending on how a firm represents the system in which it operates, it might see itself as belonging to an industry or a vertically integrated sector, and visualise opportunities and constraints accordingly. In a similar fashion, workers in a given industry might see themselves as part of a uniform block of labour across industries and therefore opposed to capitalists across industries, or as part of their industry and therefore allied with the capitalists of the industry against the interests of other industries. Depending on such representations and the actions that are taken as a result, different paths of structural change may be activated out of those which are possible in a given situation.

Therefore, in order to obtain a closer approximation of actual paths of structural change, we need to look at how actions take place within structures. As we discussed above, structures follow principles of proportionality that make certain motions feasible and others unfeasible by the principle of relative structural invariance. Hence, structures identify the range of feasible actions, but they do not determine which actions are made under the specific constraints and opportunities. Structures, however, may also play a more direct role in orienting actions (Cardinale, 2018 c, d). Here we must distinguish between the position that a given actor occupies in structures at a given moment and the positions occupied over time. A position occupied at a given moment is associated with constraints and opportunities. As we saw above, this depends on how actors represent the system (e.g. in a horizontal or vertical fashion) and their position therein. Such representation may in turn depend on the actor's history of positioning. In fact, by occupying positions within structures over time, actors develop a propensity to visualise some opportunities and constraints as more salient than others, and 
are therefore more oriented towards visualising those rather than others. As a result, even actors that occupy the same position at a given moment might represent the system differently, because their history of positioning may be different.

This approach to the explanation of structural change presupposes a plural causality framework: existing structures determine feasible causal paths while individual or collective actions trigger some of those paths, but what paths are triggered in turn depends on positions within structures at a given moment and over time. This may also result in new structures being generated with the corresponding opportunities and constraints for further actions. However, even when such positions and their influence on actions are considered, the theory may explain the feasibility range for actions but cannot fully account for what actions actually take place, i.e. what possibilities turn into actual actions (Cardinale, 2018a, b, c, d). In other words, even considering the orienting effect of structures on action, structures cannot be seen as determining action.

In fact, actors constantly need to use their existing categories, formed through previous action with structures, to interpret unfolding situations, which are never exactly the same as those already encountered. Therefore, agency is constantly involved in the categorization of unfolding experience and the selection of courses of action among those which are compatible with that categorization (Emirbayer and Mische, 1998; Cardinale, 2018c).

\section{Conclusion}

Theories of structural change study the relationship between changes in the magnitude of economic variables and changes in their composition. Such analysis relies on the criterion of relative structural invariance, whereby not all system components change at the same time or speed. This makes it possible to specify the range of variations afforded by given structures. However, in order to move from identifying a set of possibilities for change to describing a specific path out of those which are possible, theories of structural change rely on explicit or implicit assumptions about actions taking place within those structures. In our reading, this suggests that structural change is open-ended: economic structures in a given situation afford a variety of change paths, but it is the actions that actually take place within those structures that activate one path of change out of those which are possible. Therefore, theories of structural change should be interpreted as identifying possibilities for change, rather than specifying specific paths thereof.

In order to understand structural change taking place in actual historical situations, we need to move to a different way of identifying which path of change will actually take place out of those which are made possible by structures: instead of making assumptions about actions, we need to 
consider how actual actions take place within structures. We have shown that the same economic structures can be represented in different ways by the actors operating within them, so that structures cannot univocally determine actions. This provides a cogent argument for why structural change is inherently open-ended: structures can ex ante only specify possibilities but not the courses of action actually undertaken. However, we can explain why certain actions have been taken, and why certain consequences have arisen, after the multiple causal paths involved in the process under consideration have worked themselves out. Explaining structural change thus requires us to look at the interface between theory, which addresses the configuration and dynamics of structural constraints and opportunities, and history, which may ‘close’ open-endedness in different ways depending on context.

\section{References}

Aftalion, A. (1913) Les crises périodiques de surproduction, Paris, Rivière.

Aftalion, A. (1927) 'The Theory of Economic Cycles based on the Capitalistic Technique of Production', Review of Economic Statistics (then Review of Economics and Statistics), October, pp. 165-70.

Baldone, S. (1996) 'Vertical Integration, the Temporal Structure of Production, in M. Landesmann and R. Scazzieri (eds.), Production and Economic Dynamics, Cambridge, Cambridge University Press, pp. 81-104.

Baranzini, M. and Scazzieri, R. (1990) 'Economic Structure: Analytical Perspectives', in M. Baranzini and R. Scazzieri (eds.), The Economic Theory of Structure and Change, Cambridge, Cambridge University Press, pp. 227-333.

Bellino, E., Nerozzi, S. and Zoia, M.G. (2018) 'Introduction to Luigi Pasinetti’s

"Causality and Interdependence in Econometric Analysis and in Economic Theory", Structural Change and Economic Dynamics, https://doi.org/10.1016/j.strueco.2018.09.007.

Besomi, D. (2007) 'Mentor Bouniatian on Cycles and Equilibrium', Structural Change and Economic Dynamics, 18 (1), pp. 120-43.

Bianchi, P. (1984) Divisione del lavoro e ristrutturazione industriale, Bologna, Il Mulino.

Bohm-Bawerk, E. von (1889) Positive Theorie des Kapitales (part 2: Kapital und Kapitalzins), Innsbruck, Wagner. (English translation: Positive Theory of Capital, London, Macmillan, 1891).

Boisguillebert, P. de (1843 [1707]) 'Factum de la France', in E. Daire (ed.), Economistes financiers du XVIIIe siècle, Paris, Guillaumin, pp. 267-351. 
Bouniatian, M. (1922 [1907]) Les crises économiques: essai de morphologie et théorie des crises économiques périodiques et de théories de la conjuncture économique, trans. J. Bernard. Paris: M. Giard.

Bouniatian, M. (1928) 'The Theory of Economic Cycles based on the Tendency toward Excessive Capitalization', Review of Economic Statistics, 10 (2, May), pp. 67-79.

Cardinale, I. (2018a) 'Structural Political Economy', in I. Cardinale and R. Scazzieri (eds.), The Palgrave Handbook of Political Economy, Palgrave Macmillan, pp. 769-784.

Cardinale, I. (2018b) 'A Bridge over Troubled Water: A Structural Political Economy of Vertical Integration’, Structural Change and Economic Dynamics, 46 (September), pp. 172-179.

Cardinale, I. (2018c) 'Beyond Constraining and Enabling: Toward New Microfoundations for Institutional Theory’, Academy of Management Review, 43 (1), pp. 132- 155.

Cardinale, I. (2018d) 'Microfoundations of Institutions and the Theory of Action'. Academy of Management Review, pre-published online, https://doi.org/10.5465/amr.2018.0339

Cardinale, I. and Scazzieri, R. (2016) 'Structural Liquidity: The Money-Industry Nexus', Structural Change and Economic Dynamics, 39 (C), pp. 46-53.

Cardinale, I. and Scazzieri, R. (2017) 'Beyond “Austerity vs. Expansion”: Elements for a Structural Theory of Liquidity Policy’, Revue d'économie industrielle, 160, pp. 107-136.

Dahmén, E. (1970 [1950]) Entrepreneurial activity and the development of Swedish industry, 19191939; translated by Axel Leijonhufvud, Homewood, R. D. Irwin (Original title: Svensk industriell företagarverksamhet: kausalanalys av den industriella utvecklingen 1919 - 1939, Stockholm: Almqvist \& Wiksell, 1950).

Dahmén, E. (1984) 'Schumpeterian Dynamics: Some Methodological Notes’, Journal of Economic Behaviour and Organization, 5, pp. 25-34.

Dahmén, E. (1988) “"Development Blocks” in Industrial Economics, Scandinavian Economic History Review, 3 (1), pp.3-14.

Emirbayer, M., and Mische, A. (1998) 'What is agency?', American Journal of Sociology, 103, pp. 962-1023.

Gellner, E. (1998) Language and Solitude. Wittgenstein, Malinowski and the Habsburg Dilemma, Cambridge, Cambridge University Press.

Glennan, S.S. (1996) 'Mechanisms and The Nature of Causation”' Erkenntnis, 44, pp. 49-71.

Glennan, S.S. (2010) 'Mechanisms, Causes, and the Layered Model of the World', Philosophy and Phenomenological Research, 81, pp. 362-381.

Glennan, S.S. (2017) The New Mechanical Philosophy, Oxford, Oxford University Press. 
Hagemann, H. and Scazzieri, R. (2009) 'Capital Structure and Economic Transitions: An Introductory Essay’, in H. Hagemann and R. Scazzieri (eds.), Capital, Time and Transitional Dynamics, Abingdon, Oxon., and New York, pp. 1-39.

Hawkins, D. and Simon, H. (1949) 'Note: Some Conditions of Macroeconomic Stability', Econometrica, 17, pp. 245-48.

Hayek, F.A. von (1931) Prices and Production, with a foreword by Lionel Robbins, London, Routledge and Kegan Paul.

Hayek, F.A. von (2008 [1941]) The Pure Theory of Capital, vol. XII of The Collected Works of F.A. Hayek, ed.by L. H. White, New York and London, Routledge.

Hicks, J. (1965) Capital and Growth, Oxford, Clarendon Press.

Hicks, J. (1973) Capital and Time. A Neo-Austrian Theory, Oxford, Clarendon Press.

Hicks, J. (1977) 'An Addendum to Capital and Time’, in J. Hicks, Economic Perspectives. Further Essays on Money and Growth, Oxford, Clarendon Press, pp. 190-95.

Hicks, J. (1985) Methods of Dynamic Economics, Oxford, Oxford University Press.

Keynes, J.M. (1973 [1939] 'Preface to the French edition', in J.M. Keynes, The General Theory of Employment, Interest and Money, vol. VII of The Collected Writings of John Maynard Keynes, eds. E. Johnson and D. Moggridge, Cambridge, Cambridge University Press for the Royal Economic Society, pp. xxxi-xxxv.

Landesmann, M. and Scazzieri, R. (1990) 'Specification of Structure and Economic Dynamics', in M. Baranzini and R. Scazzieri (eds.) The Economic Theory of Structure and Change, Cambridge, Cambridge University Press, pp. 95-121.

Landesmann, M. and Scazzieri, R. (1996) 'The Production Process: Description and Analysis', in M. Landesmann and R. Scazzieri (eds.), Production and Economic Dynamics, Cambridge, Cambridge University Press, pp.191-228.

Leon, P. (1967) Structural Change and Growth in Capitalism, Baltimore, Johns Hopkins University Press.

Leontief, W. W. (1928) 'Die Wirtschaft als Kreislauf', Archiv fur Sozialwisenschaft und Sozialpolitik, 60, pp. 577-623. (Partial English translation: 'The Economy as a Circular Flow', Structural Change and Economic Dynamics, 2(1), pp. 181-212.)

Leontief, W. W. (1941) The Structure of the American Economy, 1919-1939. An Empirical Application of Equilibrium Analysis, Cambridge, Mass., Harvard University Press.

Lhomme, J. (1945) 'La méthode des recherches chez Albert Aftalion', in L'œuvre scientifique d’Albert Aftalion (1945), préface by G. Pirou, Paris, Domat-Montchrestien, pp. 17-32.

Lowe, A. (1976) The Path of Economic Growth, Cambridge, Cambridge University Press. 
Lowe, A. (1977) On Economic Knowledge. Toward a Science of Political Economics, enlarged edition, Armonk, New York and London, Sharpe.

Marx, K. (1978 [1 ${ }^{\text {st }}$ English edn.1887)]) Capital: A Critique of Political Economy, vol.2, introduced by E. Mandel, translated by D. Fernbach, Harmondsworth, Penguin Books.

Myrdal, G. (1939) Monetary Equilibrium, London, Edinburgh and Glasgow, William Hodge and Company.

Neumann, J. von (1935-37) 'Über ein Ökonomisches Gleichungs-System und eine Verallgemeinerung des Brouwerschen Fixpunktsatzes', in Ergebnisse eines Mathematischen Kolloquiums, Vienna, vol. viii, pp. 73-83. (English translation: 'A Model of General Equilibrium', The Review of Economic Studies, 9, pp. 1-9.)

Nurkse, R. (1935) 'The Schematic Representation of the Structure of Production', The Review of Economic Studies, 2, pp. 232-44.

Pasinetti, L. (1965) 'A New Theoretical Approach to the Problems of Economic Growth', in Econometric Approach to Development Planning, Amsterdam, North-Holland Publishing Company, pp. 571-696.

Pasinetti, L.L. (1980 [1973]) 'The Notion of Vertical Integration in Economic Analysis', in L.L. Pasinetti, ed., Essays on the Theory of Joint Production, London and Basingstoke, Macmillan, pp. 16-43.

Pasinetti, L.L. (1981) Structural Change and Economic Growth: A Theoretical Essay on the Dynamics of the Wealth of Nations, Cambridge, Cambridge University Press.

Pasinetti, L.L. (1988) 'Growing Subsytems, Vertically Hyper-Integrated Sectors and the Labour Theory of Value', Cambridge Journal of Economics, 12, pp. 125-34.

Pasinetti, L.L. (1993) Structural Economic Dynamics: A Theory of the Economic Consequences of Human Learning, Cambridge, Cambridge University Press.

Pasinetti, L.L. (2007) Keynes and the Cambridge Keynesians: a "Revolution in Economics" to be Accomplished, Cambridge, Cambridge University Press.

Pasinetti, L.L. (2018 [1965]) 'Causality and Interdependence in Econometric Analysis and in Economic Theory’, Structural Change and Economic Dynamics, https://doi.org/10.1016/j.strueco.2018.09.008.

Pearl, J. (2009) Causality: Models, Reasoning and Inference, second edition, Cambridge, Cambridge University Press.

Quadrio Curzio A. (1967) Rendita e distribuzione in un modello economico plurisettoriale, Milano, Giuffrè.

Quadrio Curzio, A. (1975) Accumulazione del capitale e rendita, Bologna, Il Mulino. 
Quadrio Curzio, A. (1986) 'Technological Scarcity. An Essay on Production and Structural Change', in M. Baranzini and R. Scazzieri (eds.) Foundations of Economics. Structures of Inquiry and Economic Theory, Oxford and New York, Basil Blackwell, pp. 311-38.

Quadrio Curzio, A. (1996) 'Production and Efficiency with Global Technologies', in M. Landesmann and R. Scazzieri (eds), Production and Economic Dynamics, Cambridge, Cambridge University Press, pp. 105-126.

Quadrio Curzio, A. and Pellizzari, F. (1999) Rent, Resources, Technology, Berlin, Springer.

Quadrio Curzio, A. and Pellizzari, F. (2018) 'Political Economy of Resources, Technologies, and Rent', in I. Cardinale and R. Scazzieri (eds), The Palgrave Handbook of Political Economy, London, Palgrave Macmillan, pp. 657-704.

Quesnay, F. (1758) Tableau économique, Versailles.

Ricardo, D. (1951[1817]) On the Principles of Political Economy and Taxation, edited by P. Sraffa with the collaboration of M.H. Dobb, Cambridge, Cambridge University Press for The Royal Economic Society.

Robertson, D.H. (1915) A Study of Industrial Fluctuation; An Enquiry into the Character and Causes of the so-called Cyclical Movements of Trade, London, P. S. King.

Scazzieri, R. (1990) 'Vertical Integration in Economic Theory', Journal of Postkeynesian Economics, 13 (1, Fall), pp. 20-46.

Scazzieri, R. (1993) A Theory of Production. Tasks, Processes, and Technical Practices, Oxford, Clarendon Press.

Scazzieri, R. (2014) 'Foreword to Albert Aftalion's Essay’, Economia Politica, Vol. XXXI, n. 1, April, pp. 89-91.

Scazzieri, R. (2018a) 'Structural Dynamics and Evolutionary Change', Structural Change and Economic Dynamics, forthcoming.

Scazzieri, R. (2018b) ‘Between Theory and History: The Structural Dynamics Tradition’, in A. Sinha (ed.), Economics and its History, Delhi, Routledge, forthcoming.

Scazzieri, R., Baranzini, M. and Rotondi, C. (2015) 'Resources, Scarcities and Rents: Technological Interdependence and the Dynamics of Socio-Economic Structures', in M. Baranzini, C. Rotondi and R. Scazzieri (eds.), Resources, Production and Structural Dynamics, Cambridge, Cambridge University Press, pp. 427-484.

Schäffle, A. (1896) Bau und Leben des sozialen Körpers, 2nd edn, Tübingen, Lauppschen.

Smith, A. (1976 [1776]) An Inquiry into the Nature and Causes of the Wealth of Nations, General Editors R.H. Campbell and A.S. Skinner, Textual Editor W.B. Todd, vol. I, Oxford, Oxford University Press. 
Sraffa, P. (1960) Production of Commodities by Means of Commodities. Prelude to a Critique of Economic Theory, Cambridge, Cambridge University Press.

Tugan Baranovsky, M.I. (1894) Promyshlennye Krizisy v sovremennoi Anglii, St. Petersburg, I.M. Skorochodova.

Tugan Baranovsky, M.I. (1913 [1900]) Crises industrielles en Angleterre, translated from the 2nd revised and augmented Russian edn. by Joseph Schapiro, Paris, Giard et Brière (1st Russian edn. 1894; 2nd Russian edn. 1900). 